\title{
Mis-infodemic: The Achilles' heel in combating the COVID-19 pandemic in an Indian perspective
}

\author{
Soumya Swaroop Sahoo', Dinesh Prasad Sahu², Ankita Kankaria ${ }^{1}$ \\ ${ }^{1}$ Department of Community Medicine and Family Medicine, All India Institute of medical Sciences, Bathinda; \\ ${ }^{2}$ Department of Community Medicine and Family Medicine, All India Institute of medical Sciences, Bhubaneswar, India
}

\begin{abstract}
In this ongoing SARS-CoV2 Corona virus pandemic, we are witnessing an uninhibited spread of mis-information on various social media platforms. This spread of mis-information or "misinfodemic" is playing a negative role in our fight against the virus with far reaching consequences. International organizations like the WHO and other governmental organizations have geared up to the occasion to limit the spread of these and bring clarity in this context. In this time of crisis, risk communication is vital in the communication between organizations/government and the people. But apart from the organizations, the onus is on the people and media to realise the importance and verify the authenticity of information being circulated. It is imperative that information, being a double edged sword, is handled with caution and effective communication strategies are devised for the dissemination of accurate and scientific health related information. Social media can be used in a constructive way in mitigating the effects of this pandemic for the betterment of the society.
\end{abstract}

Correspondence: Dinesh Prasad Sahu, Senior Resident Community Medicine, All India Institute of Medical Sciences, Bhubaneswar 751019, India.

Tel. +91.9861690396 .

E-mail: dineshprasad.sahu@yahoo.in

Key words: Infodemics; pandemic; COVID; coronavirus; information

Authors' contributions: All the authors made a substantive intellectual contribution. All the authors have read and approved the final version of the manuscript and agreed to be accountable for all aspects of the work.

Funding: None.

Conflict of interest: None of the author has any competing interest.

Received for publication: 24 May 2020.

Accepted for publication: 27 May 2020.

${ }^{\text {CC }}$ Copyright: the Author(s), 2020

Licensee PAGEPress, Italy

Monaldi Archives for Chest Disease 2020; 90:1405

doi: 10.4081/monaldi.2020.1405

This article is distributed under the terms of the Creative Commons Attribution Noncommercial License (by-nc 4.0) which permits any noncommercial use, distribution, and reproduction in any medium, provided the original author(s) and source are credited.

\section{Introduction}

The novel Corona virus (COVID-19) continues to spread across the world, affecting as many as 213 countries [1]. The onset of this pandemic has brought an unprecedented rise of information from various sources on different platforms. The majority of this information available in the public domain is retrieved from unscientific sources. This plethora of misinformation tends to be speculative but creates confusion and mistrust among the public. Moreover, this impedes effective public health response to COVID 19. This phenomenon has been termed as "infodemic" by the World Health Organization (WHO) [2]. According to the words of the WHO Director-General Tedros Adhanom Ghebreyesus, "We are not just fighting an epidemic; we are fighting an infodemic" [3].

\section{Why do we need to worry about the mis-infodemics?}

Worldwide, there has been an increase in the usage of smart phone and technology with increased accessibility and affordability of internet. Likewise, India at present is the largest and fastestgrowing market for digital consumers according to the report of the 'Digital India- Technology to transform a Connection Nation'. India now stands next only to China in the total number of internet users with nearly 560 million subscribers [4]. The uptake of Social media platforms such as WhatsApp, Facebook, YouTube, and Twitter has increased even in rural India. The pandemic related information available on these platforms gets disseminated without verification and spreads even faster than the virus itself. This spread of misinformation can create a sense of panic and fearmongering among the people. Additionally misinformation in disease control measures for example on Measles vaccine (in America, Eastern Mediterranean region and Europe) or Ebola containment (in West Africa) has resulted in increase in morbidity and mortality due to these diseases [5].

Ironically, rumours not only originate from social media, scientific researches with a lack of proper evidence also contribute to this. At this critical juncture, the right information from reliable sources remains a prerequisite.

\section{Impact of misinfodemic}

Our knowledge about the virus is in an evolving stage with new facts and scientific evidence arising every day about this novel virus and its interactions with humans. This makes it all the more vulner- 
able, as people are on a lookout for more information amidst this vacuum. At present, the whole of India is in lockdown as a containment measure to limit the spread of the virus. This further leads to the frequent use of social media/technology to explore more about this disease regarding its symptoms, prevention, cure, and most importantly, its impact on the future course of action. So, it's along expected lines that the two most talked topics of recent times are under the hashtag of \#covid19 and \#coronavirus taking the count to over 3 billion posts and over 100 billion interactions [6].

This mis-infodemic is negatively affecting people's routine, their behaviour, and overall wellbeing. If we take an example of hygiene practices, there is a flooding of information on the frequency of hand washing, how to wash consumable items or packets, disinfecting homes, etc. This compelled people to unnecessarily hoard the chemical disinfectants and cleaning products. Similarly, information on closure of shops during lockdown resulted in buying and stocking of excess vegetables or groceries. Amidst this ignorance and increased uncertainty about disease adds an element of helplessness and fear. This opened the business of false claims about miracle cures or unproven natural remedies that people have fallen prey of [7]. Overall, this misinformation has created a wave of anxiety and stress among people. Moreover, people with pre-existing mental conditions like anxiety and obsessive-compulsive disorder are suffering the most. And to make matters worse, the rumours and spread of misinformation has apparently led to attacks on healthcare providers interfering with the process of surveillance and treatment. The pandemic is not only taking a heavy toll on the economy but also on the psychological health, behaviours, and livelihood of the people.

\section{Need of authentic source for verifiable information}

In this context, it becomes critical that people should know the source of authentic information, especially the official websites of government organizations or medical institutes. Here comes the role of risk communication in public health. In this state of crisis, where the potential impact of hazard is high, there is people's emotional response or outrage about it [8]. In this scenario, crisis risk communication must be timely, accurate, based on scientific evidence, and relevant, and it must also reassure and give people hope.

In order to address this issue, the WHO risk communication team launched WHO Information Network for Epidemics on $15^{\text {th }}$ February 2020 [9]. WHO has now started to closely track and identify the most prevalent rumours relating to the Corona virus through a campaign titled \#KnowTheFacts. In this International Fact Check Network (IFCN) organization is responsible for a double-checking of any suspicious information [10]. Google has also released its fact check methodology. The government of India has started COVID 19 Fact Check Portal. FactChecker.in is India's first dedicated fact-checking initiative to verify the information. There lies the issue that the information seeker should have an element of trust in the dispensing authority.

In this context, the Union Health Ministry and the State Health authority have stepped up to create awareness through various platforms. Health advisories are being published by the health authorities from time to time. The government has taken measures to limit the amount of misinformation in social media and highlighted the importance of risk communication. It has been communicated on the part of government that regular press briefings/ press releases will be done to keep media updated on the developments and avoid stigmatization of affected communities. At the central, state and district level, designated officials are entrusted with the responsibility of giving information about the spread of the disease and control measures. But it has to be reiterated again, that apart from standard biological protocols, local cultural contexts and beliefs need to be taken into account and strategies should be made acceptable to local communities.

\section{Responsibility of individuals, media and social media platforms}

To address the mis-infodemic challenge, responsible information exchange behaviour is expected from individuals using social media, media personnel, or news channels and national agencies. We as an individual should cross check the validity every time we read information related to corona or COVID19 and disseminate it further.

Additionally, it becomes the prime responsibility of the news media and directors of Social Media platforms to act in a constructive way limiting the spread of fake news and adopting a cautioned approach for providing a platform for dissipation of correct information.

\section{Conclusions}

"Mis-infodemics" presents a crisis in public understanding. In this world of internet technology where information is abundant, it is high time to promote digital literacy. Information is a double edged sword, so needs to be dealt with great caution. Without this understanding, it can seriously jeopardize our fight against the pandemic.

\section{References}

1. World Health Organization. Coronavirus disease (COVID-19) pandemic. 2020. Cited 2020 Apr 17. Available from: https:// www.who.int/emergencies/diseases/novel-coronavirus-2019

2. Rothstein MA, Alcalde MG, Elster NR, et al. Quarantine and isolation: Lessons learned from SARS. Diane Pub Co., 2003. Available from: https://biotech.law.lsu.edu/blaw/cdc/SARS REPORT.pdf

3. Global Health Strategies [on Twitter]. "We are not just fighting an epidemic. We are fighting an \#infodemic. Fake news spreads just as fast and easily as this virus, and it is very dangerous" Available from: https://witter.com/ghs/status/ 1228687870845689856?lang=en

4. Kakai N, Madgavkar A, Kshirsagari A, et al. Digital India: Technology to transform a connected nation [Internet]. 2019. Available from: https://www.mckinsey.com/ /media/mckinsey/business functions/mckinsey digital/our insights/digital india technology to transform a connected nation/digital-indiatechnology-to-transform-a-connected-nation-full-report.ashx

5. Allgaier J, Svalastog AL. The communication aspects of the Ebola virus disease outbreak in Western Africa-do we need to counter one, two, or many epidemics? Croat Med J 2015;56: 496-9.

6. Molla R. How coronavirus took over social media. Vox [Internet]. 2020 Mar 12; Available from: https://www.vox. 
com/recode/2020/3/12/21175570/coronavirus-covid-19social-media-twitter-facebook-google

7. The Conversation [Internet]. COVID19: Social media both a blessing and a curse during coronavirus pandemic. 2020 Mar 22; Available from: https://theconversation.com/covid19social-media-both-a-blessing-and-a-curse-during-coronaviruspandemic- 133596

8. Glik DC. Risk communication for public health emergencies. Annu Rev Public Health 2007;28:33-54.
9. WHO. Information Network for Epidemics: Novel coronavirus (2019-nCoV) outbreak 2019 - 2020 [Internet]. 2020. Available from: https://www.who.int/docs/default-source/coronaviruse/ risk-comms-updates/update-1-epi-win-ncov-0.pdf?sfvrsn= c26880ae_2

10. CBC News [Internet]. How social media platforms are fighting coronavirus misinformation. $2020 \mathrm{Feb} 11$. Available from: https://www.cbc.ca/news/technology/coronovirus-misinformation-1.5460196 